ORIGINAL ARTICLE

\title{
Prediction of total body water in infants and children
}

\author{
J C K Wells, M S Fewtrell, P S W Davies, J E Williams, W A Coward, T J Cole
}

Arch Dis Child 2005;90:965-971. doi: 10.1136/adc.2004.067538

See end of article for authors' affiliations .....................

Correspondence to: Dr J CK Wells, MRC Childhood Nutrition Research Centre, Institute of Child Health, 30 Guilford Street, London WCIN1EH, UK; J.Wells@ ich.ucl.ac.uk

Accepted 29 March 2005

\begin{abstract}
Background: In paediatric clinical practice treatment is often adjusted in relation to body size, for example the calculation of pharmacological and dialysis dosages. In addition to use of body weight, for some purposes total body water (TBW) and surface area are estimated from anthropometry using equations developed several decades previously. Whether such equations remain valid in contemporary populations is not known.

Methods: Total body water was measured using deuterium dilution in 672 subjects ( 265 infants aged $<1$ year; 407 children and adolescents aged 1-19 years) during the period 1990-2003. TBW was predicted (a) using published equations, and (b) directly from data on age, sex, weight, and height.

Results: Previously published equations, based on data obtained before 1970, significantly overestimated TBW, with average biases ranging from $4 \%$ to $11 \%$. For all equations, the overestimation of TBW was greatest in infancy. New equations were generated. The best equation, incorporating log weight, log height, age, and sex, had a standard error of the estimate of $7.8 \%$.

Conclusions: Secular trends in the nutritional status of infants and children are altering the relation between age or weight and TBW. Equations developed in previous decades significantly overestimate TBW in all age groups, especially infancy; however, the relation between TBW and weight may continue to change. This scenario is predicted to apply more generally to many aspects of paediatric clinical practice in which dosages are calculated on the basis of anthropometric data collected in previous decades.
\end{abstract}

n paediatric clinical practice, many medicines and treatments are tailored to children's size on the basis of either body weight, predicted total body water (TBW), or predicted surface area. For example, fluid and energy requirements in parenteral nutrition can be estimated on the basis of TBW, as can many pharmacological dosages ${ }^{1}$ and peritoneal dialysis dosages. ${ }^{12}$ Anecdotal evidence suggests that for many scenarios, treatment remains adjusted in relation to body weight, and little attention is directed to the composition of that weight. However, for dialysis dosages, there is increasing recognition of the importance of estimating TBW with accuracy. ${ }^{2}$ In addition to clinical practice, the prediction of TBW is also useful in paediatric research studies; for example, when applying the deuterium dose-to-the-mother method for measurement of breast milk transfer. ${ }^{34}$

Although TBW can be measured using non-radioactive stable isotopes, this procedure is rarely undertaken in clinical practice due to the lengthy duration of the procedure. TBW can be predicted instead from anthropometry, with two equations, both published several decades ago, widely used. Friis-Hansen ${ }^{5}$ derived equations from a sample of 35 infants aged $<1$ year, and 50 children aged from 1 to 13 years, with $69 \%$ of the sample being males. Mellits and Cheek $^{6}$ derived equations for 251 subjects aged $<21$ years, with their sample incorporating the data of Friis-Hansen. These equations were updated recently with the addition of 101 new data points by Morgenstern and colleagues, ${ }^{1}$ but the new equations remain heavily dependent on the older data which still comprise $70 \%$ of the sample, and the equations of Mellits and Cheek remain recommended $^{2}$ for calculation of dialysis dosages.

Equations derived in previous decades are not necessarily valid for contemporary infants and children, due to secular trends in growth and nutritional status. Many western populations are experiencing a marked increase in the prevalence of childhood obesity. ${ }^{78}$ Importantly, increases in fatness appear to be even greater than increases in body mass index (BMI). Several studies have shown an increase in fat content, ${ }^{9-11}$ and increased central distribution of fat, ${ }^{12}$ for a given BMI value. Where average body fat content has increased, the relation between anthropometry and TBW is predicted likewise to have changed. However, this issue has not received attention.

The aims of the present study were: (1) to re-evaluate existing prediction equations, in order to quantify the magnitude of bias when applied to contemporary subjects; and (2) to derive revised equations using a database of 672 infants and children measured since 1990.

\section{METHODS}

Measurements of TBW were made in several studies of body composition and energy metabolism conducted in Cambridge, UK, between 1990 and 2003. These studies have been described previously. ${ }^{13-16}$ New data have also been collected in an ongoing study of body composition in London. Ethical permission for these studies was granted by Cambridge Local Research Ethics Committee, the former MRC Dunn Nutrition Unit, and by the Ethical Committee of Great Ormond Street Hospital and the Institute of Child Health. Written informed consent was obtained from participants, or from parents in the case of minors. The protocol adhered to the Declaration of Helsinki.

Measurement of TBW by stable isotope dilution requires administration of a dose of water labelled with either ${ }^{2} \mathrm{H}$ or ${ }^{18} \mathrm{O}$. After equilibration of this dose with the body water pool is complete, the enrichment of body fluids (saliva, urine or serum) can be used to calculate the dilution space $(\mathrm{N})$ using simple dilution principles:

$$
N=\frac{T A}{a}\left(\frac{E_{a}-E_{T}}{E_{s}-E_{p}}\right)
$$

where $A$ is the dose of isotope in grams, $a$ is the portion of the dose in grams retained for mass spectrometer analysis, $T$ is the amount of tap water in which the portion $a$ is diluted before analysis, and $E_{a}, E_{t}, E_{p}$, and $E_{s}$ are the isotopic 


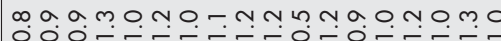

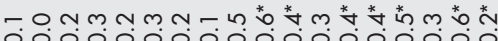
o

की

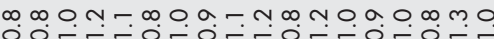

a n ง mं

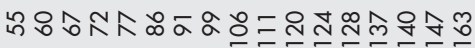

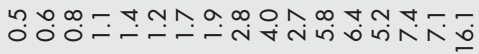

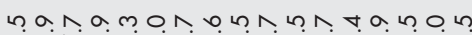
ช่ enrichments in delta units of the portion of dose, the tap water used, the pre-dose urine sample, and the post-dose urine sample. ${ }^{17}$ Delta units express isotopic enrichment relative to a standard, in this case Vienna-Standard Mean Ocean Water.

There are two approaches to calculating TBW from isotopic data, known as the plateau method and the back extrapolation method. ${ }^{17}$ In the plateau method, a single biological fluid sample is collected post-dose, and used as the value of $E_{s}$ in the above equation. In the back extrapolation method, $E_{s}$ is predicted from the washout kinetics of the isotope over several days following the dose. In adults, these two methods give very similar answers, but in infants, when water turnover is more rapid, the plateau method significantly overestimates TBW, due to dilution of the dose by unlabelled water during the equilibration period. ${ }^{18}$ In our sample, TBW was calculated by the back extrapolation method in all children and infants aged under 2 years, but by either method in children aged 2 years or older, when the two methods give values with minimal difference.

Both ${ }^{2} \mathrm{H}$ and ${ }^{18} \mathrm{O}$ overestimate TBW, due to their exchange with non-aqueous exchangeable hydrogen and oxygen. The extent of this exchange has been considered previously in both adults ${ }^{19}$ and infants. ${ }^{20}$ In adults and children, betweensubject variation in the relative ratio of the dilution spaces of the two isotopes can be attributed primarily to error in the analysis of isotopic enrichments, ${ }^{21}$ although body composition may also exert effects. Conventionally, the ${ }^{18} \mathrm{O}$ dilution space $\left(\mathrm{N}_{\mathrm{O}}\right)$ is converted to TBW by dividing by a factor of 1.01 , and the ${ }^{2} \mathrm{H}$ dilution space $\left(\mathrm{N}_{\mathrm{D}}\right)$ by dividing by a factor of 1.044. ${ }^{19} \mathrm{In}$ infants, variation in the relative overestimation of TBW by $\mathrm{N}_{\mathrm{D}}$ is partly due to the marked variability in body fatness that occurs during early life. ${ }^{20}$ However, in the present study all infants had both isotope spaces available. Infant TBW was therefore calculated as $\mathrm{N}_{\mathrm{O}} / 1.01$, and child TBW was calculated likewise where $\mathrm{N}_{\mathrm{O}}$ was available, or otherwise as $\mathrm{N}_{\mathrm{D}} / 1.044$.

Age, gender, weight, and height were recorded in all subjects. In infants, weight was recorded accurate to $20 \mathrm{~g}$ using Seca 727 electronic scales. Length was recorded using a Harpenden infantometer. In children, weight was measured on electronic scales accurate to $0.01 \mathrm{~kg}$, and height using portable or wall mounted stadiometers. Body mass index (BMI) was calculated as weight $(\mathrm{kg})$ divided by the square of height $(\mathrm{m})$. Data on weight, height, and BMI were converted into standard deviation scores (SDS), using UK 1990 reference data. ${ }^{22}$ Data from the samples of Friis-Hansen ${ }^{5}$

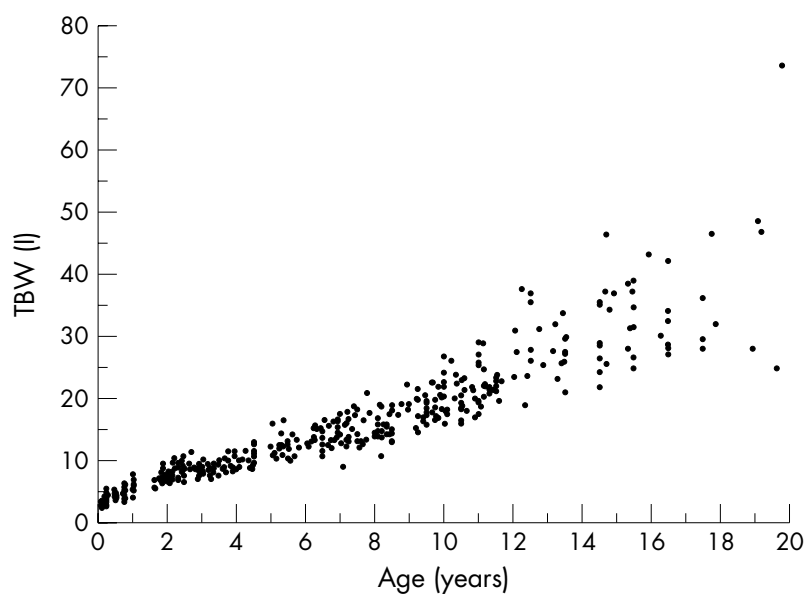

Figure 1 Plot of total body water (litres) against age in 672 infants and children. 
and Mellits and Cheek ${ }^{6}$ were also converted to SDS format for comparison.

The equations of Friis-Hansen are age specific, as follows:

- $T B W=k\left(W T^{0.790}\right)\left(H T^{0.425}\right)$

where $W T$ is weight in $\mathrm{kg}$, HT is height in $\mathrm{cm}$, and the value of $k$ is 0.177 for subjects aged 11 days to 0.5 years; 0.153 for subjects 0.5 to 2 years; 0.195 for subjects aged 2 years to 7 years; and 0.150 for subjects aged 7 to 16 years.

The equations of Mellits and Cheek are height and sex specific, as follows:

- Boys $\leqslant 132.7 \mathrm{~cm}:$ TBW $=-1.927+(0.465 W T)+(0.045 H T)$

- Boys $\geqslant 132.7 \mathrm{~cm}: T B W=-21.993+(0.406 W T)+(0.209 H T)$

- Girls $\leqslant 110.8 \mathrm{~cm}: T B W=0.076+(0.507 W T)+(0.013 H T)$

- Girls $\geqslant 110.8 \mathrm{~cm}: T B W=-10.313+(0.252 W T)+(0.154 H T)$

The new age and sex specific equations of Morgenstern et al (2002) were also evaluated, and are as follows:

- Infants 0-3 mth: TBW $=0.887(W T)^{0.83}$

- Boys 3 mth-13 y: TBW $=0.846(W T . H T)^{0.83}$

- Girls 3 mth-13 y: TBW $=0.08037(W T . H T)^{0.65}$

- Boys >13 y: TBW $=0.0758(W T . H T)^{0.69}$

- Girls >13 y: TBW $=0.063672(W T . H T)^{0.69}$

Agreement between predicted and measured values was assessed using the method of Bland and Altman. ${ }^{24}$

For the derivation of new equations, data on total body water, weight, and height were transformed to natural log values to obtain a normal distribution. Initial models included a single term $(\log W \mathrm{~T}$ or $\operatorname{logHT}$, with weight in $\mathrm{kg}$ and height in $\mathrm{cm}$ ) for the prediction of logTBW, with further models adding terms (first the combination of logWT and $\log \mathrm{HT}$, then adding in age in years and sex (males =0; females =1) ) in order to evaluate their effect on the $r^{2}$ value and standard error of the estimate (SEE).

To cross-validate the equations, TBW was measured in a further 35 additional children aged 3-11 years, and the bias of TBW predicted using the new equations assessed.

\section{RESULTS}

\section{Description of the sample}

Table 1 presents a description of the sample of 672 individuals according to age and sex, and weight, height, and BMI status relative to current UK reference data. Due to the comparatively low number of adolescents, those aged 1219 years are considered as a single age category. Weight SDS averaged 0.2 (SD 1.0) in the whole sample, up to 11 years, ranging from -0.1 at 6 months to 0.5 at 4 years. Adolescents aged >11 years were consistently heavier, at 0.5 (SD 1.3) SDS. Height SD score averaged 0.2 (SD 1.0) in the whole sample, ranging from -0.1 at 8 years to 0.7 at 12 months. However, except at 12 months where the sample size was relatively small, the values were $\leqslant 0.3$. BMI SD score averaged 0.2 (SD 1.0) in the entire sample, ranging from -0.3 ( 9 months) to 0.6 ( 5 years and $>11$ years). In general, there was a trend towards increasing weight SDS, but not height SDS, with increasing age, so that the correlation between BMI SDS and age was $0.20(\mathrm{p}<0.001)$. The number of subjects with BMI SDS $>95$ th centile was 59, or $8.8 \%$ of the sample. The relation between TBW and age in the whole sample is given in fig 1 .

\section{Evaluation of published data on weight and height}

The SD scores for the Mellits and Cheek sample (which include the Friis-Hansen data and which also comprise the majority of the sample of Morgenstern et al) could be
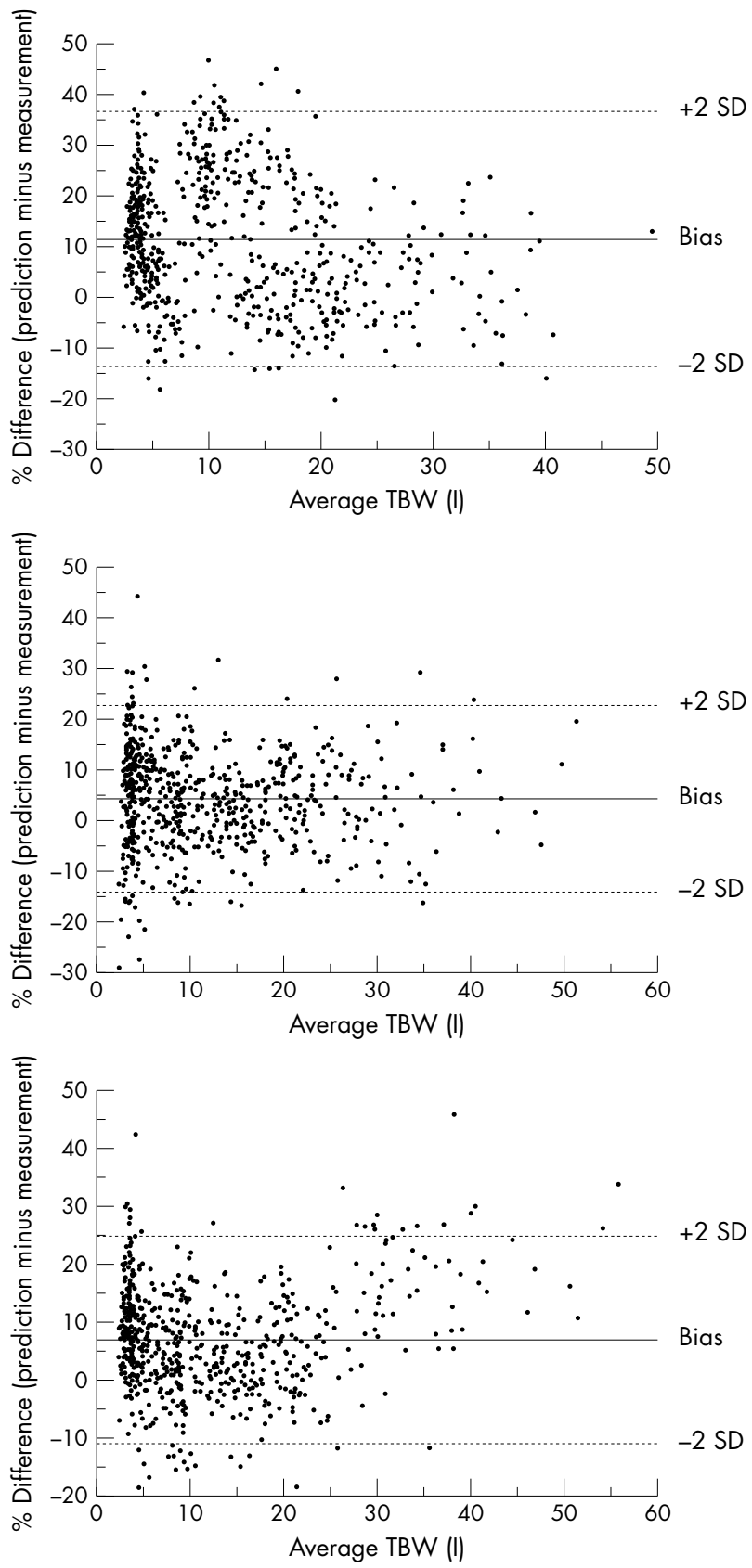

Figure 2 (A) Percent difference in TBW (predicted - measured values) using the formula of Friis-Hansen. ${ }^{4}$ (B) Percent difference in TBW (predicted - measured values) using the formula of Mellits and Cheek. ${ }^{5}$ (C) Percent difference in TBW (predicted - measured values) using the formula of Morgenstern et al.'

calculated for weight in 224 subjects, and for height and BMI in 179 subjects. On average, the sample is significantly shorter and lighter relative to current UK reference data (weight SDS: mean -0.5 , SD 1.4; height SDS: mean -0.3 , SD 1.2; BMI SDS: mean -0.5; SD 1.3; all significant at $\mathrm{p}<0.001)$. These deficits differed between the sexes for weight SDS (boys -0.3 (SD 1.3) versus girls -0.7 (SD 1.6); $\mathrm{p}=0.05$ ) and BMI SDS (boys -0.4 (SD 1.4) versus girls -0.7 (SD 1.1); $\mathrm{p}=0.08$ ); however, the sex difference in height SDS was in the opposite direction and did not approach significance (boys -0.4 (SD 1.2); girls -0.2 (SD 1.1); $\mathrm{p}=0.23$ ).

These secular trends in weight and length can be attributed to primarily to infancy, whereas the children in the sample of 
Mellits and Cheek have mean SDS values close to zero. Two effects are therefore apparent. Relative to UK 1990 reference data, the Mellits and Cheek infants have significantly reduced weight whereas the infants in our sample are representative. In contrast, the Mellits and Cheek children are similar to the 1990 reference data whereas the children in our sample are significantly heavier. In each case, there is a mismatch in relative weight between the sample of Mellits and Cheek and our own.

\section{Evaluation of published equations for predicting TBW} Figure 2 shows the difference between predicted and measured TBW for the three equations. Details of the Bland and Altman analyses are given in tables 2 and 3. Average differences were $11.5 \%$ for Friis-Hansen, $4.0 \%$ for Mellits and Cheek, and $7.0 \%$ for Morgenstern et al, in each case highly significant. For all three equations, the overestimation was approximately twice as high in infancy as subsequently, while the Friis-Hansen and Mellits and Cheek equations also showed significantly greater bias in girls compared to boys. The confidence intervals were also high for all three equations, with errors (positive or negative) of $>15 \%$ in $40 \%$ of subjects for Friis-Hansen, 14\% for Mellits and Cheek, and $17 \%$ for Morgenstern et al. For the equations of both Friis-Hansen and Morgenstern et al there was a significant correlation between the bias and BMI SD score, while the bias was also related to the magnitude of TBW in the FriisHansen and Mellits and Cheek equations.

\section{Derivation of new predictive equations}

New equations generated from the current sample are given in table 4. Using logWT alone, logTBW was predicted with a standard error of the estimate of $9.5 \%$, with the equation accounting for $98.5 \%$ of the variability. LogHT was less successful, with a standard error of $11.2 \%$. Using the combination of $\log \mathrm{WT}$ and $\log \mathrm{HT}$, the standard error was reduced to $8.2 \%$. When age and sex were also introduced into the model, the standard error decreased to $7.8 \%$, with the equation accounting for $99.0 \%$ of the variability. There were no significant interactions of sex with weight, height, or age. The optimum equation is that incorporating age and sex terms, as the regression coefficients show that females on average have 5\% lower TBW, while for each year of age, independently of weight and height, TBW increases by $0.8 \%$. Two worked examples are given in the appendix.

The 35 children in the cross-validation assessment averaged 7.5 years (range 3-11 years). Mean (SD) was 27.6 (8.4) $\mathrm{kg}$ for weight, 124.3 (14.3) $\mathrm{m}$ for height, and 0.6 (1.2) for BMI SDS. Mean (SD) bias in predicted TBW was -0.03 (0.93) l ( $\mathrm{p}=0.83)$, and was similar in boys $(0.02$ (1.01) l; $\mathrm{p}=0.92)$ and girls $(-0.12(0.82) \mathrm{l} ; \mathrm{p}=0.60)$. There were moderate but significant correlations between the bias and age $(\mathrm{r}=0.38, \mathrm{p}=0.025)$ and BMI SDS $(\mathrm{r}=0.38, \mathrm{p}=0.026)$. There was no correlation between age and BMI SDS in these children $(r=0.08)$, and in a multiple regression model the two factors were independent significant predictors of the bias, with an $r^{2}$ value of 0.31 .

\section{DISCUSSION}

Our study shows that the use of TBW prediction equations published in previous decades significantly overestimates TBW on average, while also predicting TBW with $>15 \%$ error in a substantial proportion of subjects. These findings have implications for all aspects of paediatric clinical practice in which the prediction of TBW is used to guide treatment, and have broader relevance to scenarios where other indices of size, such as weight or surface area, are used for the same purpose.

Over recent decades, children have become heavier and fatter. Compared to US reference data collected between 1963 and 1975, we estimated that children in Cambridge measured in the 1990s were 23\% (boys) and 35\% (girls) fatter. ${ }^{11}$ This increase seems to have occurred alongside a decrease in children's lean mass, probably due to decreasing activity levels, so that underlying the change in weight there have been even more marked changes in body composition. ${ }^{11}$ To some extent, this increase in fatness is evident in greater weight, and hence greater BMI. However, several studies have shown that fat content has increased even when BMI is held constant, indicating a secular trend in fatness that is distinct from the secular trend in weight. ${ }^{9-12}$

Although secular trends in weight also appear to have occurred in infants, the increase appears to have occurred earlier-that is, prior to 1990 . Thus relative to 1990 UK reference data, the children in our sample tend to be heavier, while the infants do not differ significantly. The data of Mellits and Cheek comprise children representative of UK 1990 reference data, but their infants have SD scores significantly negative. It is not possible to conclude from this disparity whether contemporary infants are more or less healthy than those in previous decades. The important issue for our study is that, in both infants and children, there is a disparity in weight status between the subjects used to derive our equations, and those studied in previous decades.

Secular trends in size and body composition have therefore altered the relation between anthropometry and TBW, so that in the infants and children of our sample, for any given weight, a greater proportion of that weight is fat. Consequently, prediction equations derived in previous decades systematically overestimate TBW in contemporary infants and children. This effect was apparent even though our sample did not have a high level of obesity, and average BMI SDS was close to zero (0.2 SDS), though consistently higher at around 0.4 to 0.5 SDS from 5 years of age.

Two of the old equations showed a significant sex difference in accuracy, with a greater bias in girls compared to boys. This is consistent with the scenario described above, in which the trend towards increased fatness is stronger in contemporary girls than in boys. ${ }^{11}$ However, the difference may also relate to the over-recruitment of boys in the older datasets. Overall, $67 \%$ of the Mellits and Cheek sample were male, with this bias particularly evident in infants $<1$ year

Table 2 Agreement between TBW values measured using deuterium dilution and predicted from anthropometry using published equations

\begin{tabular}{|c|c|c|c|c|c|c|c|c|c|}
\hline & \multicolumn{3}{|c|}{ Absolute values (litres) } & \multicolumn{3}{|c|}{ Relative values (\%) } & \multicolumn{3}{|c|}{ Correlations (r)t } \\
\hline & $\overline{\text { Bias }}$ & $\pm 2 S D$ & p value & Bias & $\pm 2 S D$ & p value & $\overline{\text { TBW }}$ & Age & BMI SD score \\
\hline Friis-H & 1.0 & 3.5 & $<0.00$ & 11.5 & 25.1 & $<0.0001$ & $-0.34^{*}$ & -0.32 & $0.16^{*}$ \\
\hline Mellits and Cheek (1970) & 0.3 & 2.8 & $<0.0001$ & 4.0 & 18.5 & $<0.0001$ & $-0.10^{*}$ & -0.06 & 0.06 \\
\hline Morgenstern et al (2002) & 0.9 & 4.3 & $<0.0001$ & 7.0 & 18.0 & $<0.0001$ & 0.07 & $0.10^{*}$ & $0.13^{*}$ \\
\hline
\end{tabular}

${ }^{*} \mathrm{p}<0.05$.

TCorrelations between bias and other factors (magnitude of TBW, age, and BMI SD score).

$\mathrm{SD}$, standard deviation. 
Table 3 Relative biases (\%) in prediction equations according to age group and sex

\begin{tabular}{|c|c|c|c|c|c|c|c|c|c|c|}
\hline & \multicolumn{2}{|l|}{ Boys } & \multicolumn{2}{|l|}{ Girls } & \multicolumn{2}{|c|}{$0-0.99$ years } & \multicolumn{2}{|c|}{$1-4.99$ years } & \multicolumn{2}{|c|}{ 5-11 years } \\
\hline & Bias & SD & Bias & SD & Bias & SD & Bias & SD & Bias & SD \\
\hline Friis-Hansen (1957) & $9.3^{*}$ & 8.8 & 13.4 & 12.3 & 12.6 & 9.4 & 5.5 & 10.3 & 7.3 & 12.8 \\
\hline Mellits and Cheek (1970) & $2.1^{*}$ & 9.3 & 5.8 & 8.9 & 5.5 & 10.3 & 2.9 & 8.6 & 3.3 & 7.8 \\
\hline Morgernstern et al (2002) & 7.2 & 9.2 & 6.8 & 8.8 & 8.7 & 8.0 & 4.3 & 8.5 & 3.6 & 7.3 \\
\hline
\end{tabular}

*Significant difference between boys and girls, $\mathrm{p}<0.001$.

All biases significantly different from zero, $p<0.0001$.

(73\% male). ${ }^{6}$ Body composition differences between the sexes are already present at birth and continue through childhood, ${ }^{25}{ }^{26}$ hence the lack of females would have biased the data towards larger TBW for a given weight.

The subjects who comprised our sample were measured over a period of 12 years, with the infants and toddlers measured during 1990-95, and the majority of the children over 4 years measured after 1995. This is a potential limitation of our study, as it is likely that our sample differentially reflects the effect of the obesity epidemic according to when particular age groups were measured. For example, the average BMI SDS was 0.59 in adolescence, but -0.07 in infancy. Nevertheless, individual children tend to rise through the BMI centiles as they grow older. Thus, the greater BMI SDS of the older children may be attributable to a combination of their own age, and the interaction of that age with the period when they were studied. Our cross-validation assessment indicated that TBW was predicted without mean bias in children aged 3-11 years; however there was a small but significant correlation between the bias and age.

Our data also derive from a single region of the UK, with all infants and the majority of the children measured in Cambridge. This sample may not be representative of the UK, or indeed other populations overseas. In terms of the secular trends in body weight that we have identified relative to the previous published data, we believe such differences are likely to apply broadly to the UK population as a whole, with trends over time being greater than contemporary differences between regions. We are unaware of any UK studies reporting downward secular trends in children's weight and BMI, so our newer equations enable clinicians to take into account this general trend towards greater weight and fatness. Nevertheless, the relation between weight and fat content may continue to change, and our equations may be biased in specific ethnic groups. The cross-validation of our equations, using 35 children measured in the last six months, showed a non-significant mean bias in both boys and girls. However, in individuals, bias was weakly but significantly related to both BMI SDS and age, suggesting that even over a 10 year period, the relation between weight and fatness has continued to alter.

A related issue concerns the accuracy of predictive values in individuals as opposed to populations. Our best equation, based on data on weight, height, age, and sex, has a predictive error of $\sim 8 \%$, despite the high $\mathrm{r}^{2}$ value of 0.99 . Thus, predicted values for TBW may lie within $\pm 16 \%$ of the actual value, and it can be seen that there remains a real need for body composition methods more accurate than anthropometry that are suitable for routine clinical application. Thus, our study can only address population trends in body composition, and predictive equations inevitably have a significant margin of error in individuals.

Nonetheless, our findings have important implications for paediatric clinical practice, regardless of the approach by which treatment is adjusted for size. Although in some contexts dosage errors of $\pm 10 \%$ may have no detrimental effect, it is recognised that accurate prediction of TBW is required for effective dialysis. Bearing in mind the cautions discussed above, our new equations may be considered appropriate for infants and children $\leqslant 11$ years. At present, we have too few data points for adolescents to make equations for this age period with sufficient confidence; however we retained those data available within this age group $(n=64)$ in order to improve the fit of our equations towards the end of the pre-pubertal period.

Many components of paediatric clinical management are adapted from approaches originally determined in adults. This gives rise to the dilemma of how to calculate the requirements of younger age groups, with their different body proportions and higher rates of metabolism. Among the variables used to predict requirements are weight or height, predicted surface area, and predicted TBW. The optimal

\begin{tabular}{|c|c|c|c|c|c|c|}
\hline Predictor & Coefficient & SE of coefficient & $t$ & $p$ & $\begin{array}{l}\text { Standard error } \\
\text { of the estimate }\end{array}$ & $r^{2}$ \\
\hline $\begin{array}{l}\text { Constant } \\
\text { LnWT }\end{array}$ & $\begin{array}{r}-0.427 \\
0.963\end{array}$ & $\begin{array}{l}0.012 \\
0.005\end{array}$ & $\begin{array}{l}-34.1 \\
194\end{array}$ & $\begin{array}{l}<0.0001 \\
<0.0001\end{array}$ & 0.095 & 0.985 \\
\hline $\begin{array}{l}\text { Constant } \\
\text { LnHT }\end{array}$ & $\begin{array}{r}-7.329 \\
2.093\end{array}$ & $\begin{array}{l}0.052 \\
0.012\end{array}$ & $\begin{array}{l}-140 \\
181\end{array}$ & $\begin{array}{l}<0.0001 \\
<0.0001\end{array}$ & 0.112 & 0.980 \\
\hline $\begin{array}{l}\text { Constant } \\
\text { LnWT } \\
\text { LnHT }\end{array}$ & $\begin{array}{c}-3.12 \\
0.593 \\
0.812\end{array}$ & $\begin{array}{l}0.180 \\
0.025 \\
0.054\end{array}$ & $\begin{array}{l}-17.3 \\
23.9 \\
15.0\end{array}$ & $\begin{array}{l}<0.0001 \\
<0.0001 \\
<0.0001\end{array}$ & 0.082 & 0.989 \\
\hline $\begin{array}{l}\text { Constant } \\
\text { LnWT } \\
\text { LnHT }\end{array}$ & $\begin{array}{r}-2.952 \\
0.551 \\
0.796\end{array}$ & $\begin{array}{l}0.175 \\
0.025 \\
0.052\end{array}$ & $\begin{array}{l}-16.8 \\
22.1 \\
15.4\end{array}$ & $\begin{array}{l}<0.0001 \\
<0.0001 \\
<0.0001\end{array}$ & 0.078 & 0.990 \\
\hline $\begin{array}{l}\text { Female sex } \\
\text { Age }\end{array}$ & $\begin{array}{r}-0.047 \\
0.008\end{array}$ & $\begin{array}{l}0.006 \\
0.002\end{array}$ & $\begin{array}{l}-7.7 \\
4.4\end{array}$ & $\begin{array}{l}<0.0001 \\
<0.0001\end{array}$ & & \\
\hline
\end{tabular}

Weight in $\mathrm{kg}$; height in $\mathrm{cm}$; age in years; ln = natural log. 


\section{What is already known on this topic}

- In paediatric clinical practice, information about body weight, or other body dimensions (such as total body water) predicted from body weight, is often used to guide management

- In recent decades children have become heavier, with this weight gain primarily attributed to increased levels of body fat

method remains unknown, and surprisingly little attention has been directed to this issue.

As noted previously, ${ }^{1}$ surface area calculations are insensitive to changes in the proportion of body weight that is metabolically active. For example, males and females of identical weight and height will have the same calculated surface area, if anthropometric predictive formulae are used, despite the fact that their body composition is likely to be different. ${ }^{27}$ Surface area equations are also insensitive to changes in hydration status, and inappropriately respond to weight gain and fluid retention equally. ${ }^{27}$ The same limitations obviously apply to use of body weight alone.

The use of equations which predict TBW can overcome one of these limitations, since this approach aims to assess more directly the metabolically active component of weight, and can take into account the effects of sex and age on this association. However, predicted TBW cannot address variability in hydration status, nor the effects of conditions such as lipodystrophy which may alter the relation between weight and fatness.

Thus, we suggest that the prediction of TBW is more sensitive than other approaches to variability in body composition, and is likely to improve clinicians' ability to tailor treatment to size. However, any prediction equations are specific to the population that generated them, and the association between anthropometry and TBW will alter in response to secular trends in nutritional status. Thus, these equations are likely to require periodic updating if epidemiological surveys show continued increases in children's body weight.

\section{Conclusion}

The main finding of our study is that widely used equations for the prediction of TBW in paediatric clinical practice are biased, and significantly overestimate TBW, especially in infants and in girls. These biases are attributable to secular trends in the nutritional status and body fatness of infants and children, which increases the proportion of fat in weight and therefore reduces the proportion of water. Thus, we argue that the use of anthropometry to predict treatment requirements is confounded by secular trends in the relation between weight and body composition. We have produced new equations for the age range birth to 12 years; however further work is needed to address adolescents, particularly given the changes in fatness that are characteristic of puberty. Furthermore, a cross-validation sample indicates that the relation between weight and fatness continues to change. While our equations are an improvement on those published several decades previously, accurate prediction of body composition will be achieved only through alternative more direct approaches.

\section{Authors' affiliations}

J C K Wells, M S Fewtrell, J E Williams, MRC Childhood Nutrition Research Centre, Institute of Child Health, London, UK P S W Davies, Children's Nutrition Research Centre, Department of Paediatrics and Child Health, University of Queensland, Royal Children's Hospital, Brisbane, Australia

\section{What this study adds}

- Equations published in previous decades, that predict physiological parameters from weight, are now out of date and overestimate total body water and lean mass

- This finding has implications for many aspects of clinical management based on body weight, and supports the need to measure body composition in clinical practice

W A Coward, MRC Human Nutrition Research, Elsie Widdowson Laboratory, Fulbourn Road, Cambridge, UK

T J Cole, Centre for Paediatric Epidemiology and Biostatistics, Institute of Child Health, London, UK

Competing interests: none

\section{APPENDIX: WORKED EXAMPLES}

- Boy aged 4.4 years, weight $17.0 \mathrm{~kg}$, height $106 \mathrm{~cm}$, sex scored as zero:

$$
\begin{aligned}
\operatorname{lnTBW}= & -2.952+(0.551 \times \ln 17)+(0.796 \times \ln 106)+ \\
& (0.008 \times 4.4) \\
= & 2.36 \\
\text { TBW }(1)= & 10.55
\end{aligned}
$$

- Girl aged 0.23 years, weight $5.95 \mathrm{~kg}$, length $62 \mathrm{~cm}$, sex scored as 1:

$$
\begin{aligned}
\operatorname{lnTBW}= & -2.952+(0.551 \times \ln 5.95)+(0.796 \times \ln 62) \\
& -0.047+(0.008 \times 0.23) \\
= & 1.27 \\
\text { TBW }(1)= & 3.56
\end{aligned}
$$

\section{REFERENCES}

1 Morgenstern BZ, Mahoney DW, Warady BA. Estimating total body water in children on the basis of height and weight: a reevaluation of the formulas of Mellits and Cheek. J Am Soc Nephrol 2002;13:1884-8.

2 NKF-DOQI. Clinical practice guidelines for peritoneal dialysis adequacy. Am J Kidney Dis 1997;30:S67-136.

3 Coward WA, Cole TJ, Sawyer MB, et al. Breast-milk intake measurement in mixed-fed infants by administration of deuterium oxide to their mothers. Hum Nutr Clin Nutr 1982;36:141-8.

4 Haisma $\mathrm{H}$, Coward WA, Albernaz $\mathrm{E}$, et al. Breast milk intake and energy requirements in exclusively, predominantly and partially breast-fed infants. Eur J Clin Nutr 2003;57:1633-42.

5 Friis-Hansen BJ. Changes in body water during growth. Acta Paediatr 1957;46(suppl 110): 1-68.

6 Mellits ED, Cheek DB. The assessment of body water and fatness from infancy to adulthood. Monogr Soc Res Child Dev 1970;35:12-26.

7 Troiano RP, Flegal KM, Kuczmarski RJ, et al. Overweight prevalence and trends for children and adolescents: the National Health and Nutrition Examination Surveys, 1963 to 1991. Arch Pediatr Adolesc Med 1995; 149:1085-91.

8 Reilly JJ, Dorosty AR. Epidemic of obesity in UK children. Lancet 1999;354:1874-5.

9 Flegal KM. Defining obesity in children and adolescents: epidemiologic approaches. Crit Rev Food Sci Nutr 1993;33:307-12.

10 Moreno LA, Fleta J, Sarria A, et al. Secular changes in body fat patterning in children and adolescents of Zaragoza (Spain), 1980-1995. Int J Obes 2001;25: 1656-60.

11 Wells JCK, Coward WA, Cole TJ, et al. The contribution of fat and fat-free tissue to body mass index in contemporary children and the reference child. Int J Obes 2002;26:1323-8.

12 Moreno LA, Fleta J, Sarria A, et al. Secular increases in body fat percentage in male children of Zaragoza, Spain, 1980-1995. Prev Med 2001;33:357-63.

13 Wells JCK, Davies PSW. Estimation of the energy cost of physical activity in infancy. Arch Dis Child 1998;78:131-6.

14 Wells JCK, Fuller NJ, Dewit O, et al. Four-component model of body composition in children: density and hydration of fat free mass and comparison with simpler models. Am J Clin Nutr 1999;69:904-12.

15 Davies PS, Gregory J, White A. Physical activity and body fatness in preschool children. Int J Obes 1995;19:6-10.

16 Rennie KL, Jebb SA, Wright A, et al. Secular trends in under-reporting in young people. Br J Nutr 2005;93:241-7.

17 Coward WA. Calculation of pool sizes and flux rates. In: Prentice AM, eds. The doubly-labelled water method for measuring energy expenditure. Technical 
recommendations for use in humans. Vienna: International Dietary Energy Consultancy Group, International Atomic Energy Agency, 1990:48-68.

18 Davies PSW, Wells JCK. Calculation of total body water in infancy. Eur J Clin Nutr 1994:48:490-5

19 Racette SB, Schoeller DA, Luke AH, et al. Relative dilution spaces of $2 \mathrm{H}$ - and 180-labeled water in humans. Am J Physiol 1994;267:E585-90.

20 Wells JCK, Ritz P, Davies PSW, et al. Factors affecting the $2 \mathrm{H}$ to 180 dilution space ratio in infants. Pediatr Res 1998;43:467-71.

21 Coward WA, Ritz P, Cole TJ. Revision of calculations in the doubly labeled water method for measurement of energy expenditure in humans. Am J Physiol 1994;267:E805-7.
22 Freeman JV, Cole TJ, Chinn S, et al. Cross sectional stature and weigh reference curves for the UK, 1990. Arch Dis Child 1995;73:17-24.

23 Cole TJ, Freeman JV, Preece MA. Body mass index reference curves for the UK, 1990. Arch Dis Child 1995:73:25-9.

24 Bland JM, Altman DG. Statistical methods for assessing agreement between two methods of clinical measurement. Lancet 1986;i:307-10.

25 Rodriguez G, Samper MP, Ventura P, et al. Gender differences in newborn subcutaneous fat distribution. Eur J Pediatr 2004;163:457-61.

26 Fomon SJ, Haschke $\mathrm{F}$, Ziegler EE, et al. Body composition of reference children from birth to age 10 years. Am J Clin Nutr 1982;35:1169-75.

27 Tzamaloukas AH. In search of the ideal V. Perit Dial Int 1996;16:345-6.

\section{ARCHIVIST}

\section{Ethics and paediatric research}

In medical research on human subjects, considerations related to the well being of the human subject should take precedence over the interests of science and society.

World Medical Association (WMA), Helsinki Declaration, 2000.

People with parental responsibility...cannot agree to any intervention contrary to the child's best interests.

British Medical Association (BMA), 2004.

A research procedure which is not intended directly to benefit the child subject is not necessarily either unethical or illegal.

Royal College of Paediatrics and Child Health (RCPCH), 2000.

We believe that research in which children are submitted to more than minimal risk with only slight, uncertain or no benefit to themselves deserves serious ethical consideration.

$\mathrm{RCPCH}, 2000$.

When there is ethical and scientific justification to conduct research with individuals incapable of giving informed consent, the risk from research interventions that do not hold out the prospect of direct benefit for the individual subject should be no more likely and not greater than the risk attached to routine medical or psychological examination of such persons. Slight or minor increases above such risk may be permitted when there is an overriding scientific or medical rationale for such increases and when an ethical review committee has approved them.

Council for International Organizations of Medical Sciences (CIOMS), 2002.

$\mathrm{n}$ discussing the ethics of research involving children incapable of giving informed consent, S D Edwards and M McNamee ( $J$ Med Ethics 2005;31:351-4) examine the guidance offered by the BMA, the RCPCH, and the CIOMS in the light of the WMA Helsinki Declaration; they regard the latter as the reference standard. In support of the WMA they quote Kant; you should:

....always treat humanity, whether in your own person or in the person of any other, never simply as a means, but always at the same time as an end.

They conclude that the BMA, RCPCH, and CIOMS statements are incompatible with the WMA declaration and too permissive.

They take the BMA to task for stating that an intervention should not be contrary to the child's best interests; it should, they say, be in the child's best interests. They point to a change in the RCPCH guidelines for research not beneficial to the individual child; such research involving (for instance) venepuncture was initially considered unethical but now only "deserves serious ethical consideration". The CIOMS guideline clearly allows research procedures that involve a low degree of risk. Edwards and McNamee question the possibility of therapeutic research (research of direct benefit to the participant). If, as they seem inclined to accept, all research is non-therapeutic and any discomfort or risk is counter to the individual's well being, then it follows that all clinical research falls foul of either the WMA (the well being of the subject) or Kant (means to an end). They insist, however, that they have "refrained from advancing this radical claim". [The extract from Kant seems to deny the possibility of any valid consent for non-therapeutic research since it is using people as "a means to an end"; but it seems doubtful that Kant was thinking of research on children (or any other kind of research) when he wrote it. (It also seems to rule out any form of altruism.)] They call upon the BMA, the RCPCH, and the CIOMS to square their views with those of the WMA.

Edwards and McNamee begin their article by listing reasons why research on young children is desirable; they then stop barely short of calling it unethical. Something's got to give. Are the views of the WMA and the other three bodies as incompatible as these authors imply? It seems to me that they are not. What, after all, are "considerations relating to the well being of the human subject" and does "take precedence over" necessarily mean preclude? 